
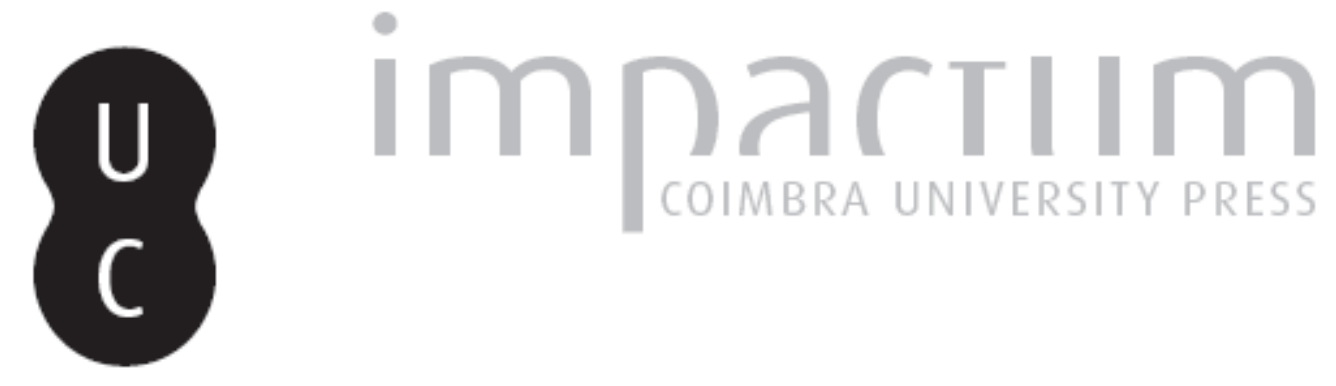

\title{
Edificar pela dissertação: nexos de coerência entre elaboração do projecto final e redacção da dissertação no mestrado integrado em arquitectura
}
Autor(es):
Rapagão, João Paulo; Malheiro, Miguel; Delgado, João Paulo
Publicado por: Editorial do Departamento de Arquitetura
URL
persistente:
URI:http://hdl.handle.net/10316.2/37297
DOI:
DOI:http://dx.doi.org/10.14195/1647-8681_4_39
Accessed : $\quad$ 26-Apr-2023 12:02:41

A navegação consulta e descarregamento dos títulos inseridos nas Bibliotecas Digitais UC Digitalis, UC Pombalina e UC Impactum, pressupõem a aceitação plena e sem reservas dos Termos e Condições de Uso destas Bibliotecas Digitais, disponíveis em https://digitalis.uc.pt/pt-pt/termos.

Conforme exposto nos referidos Termos e Condições de Uso, o descarregamento de títulos de acesso restrito requer uma licença válida de autorização devendo o utilizador aceder ao(s) documento(s) a partir de um endereço de IP da instituição detentora da supramencionada licença.

Ao utilizador é apenas permitido o descarregamento para uso pessoal, pelo que o emprego do(s) título(s) descarregado(s) para outro fim, designadamente comercial, carece de autorização do respetivo autor ou editor da obra.

Na medida em que todas as obras da UC Digitalis se encontram protegidas pelo Código do Direito de Autor e Direitos Conexos e demais legislação aplicável, toda a cópia, parcial ou total, deste documento, nos casos em que é legalmente admitida, deverá conter ou fazer-se acompanhar por este aviso.

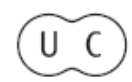




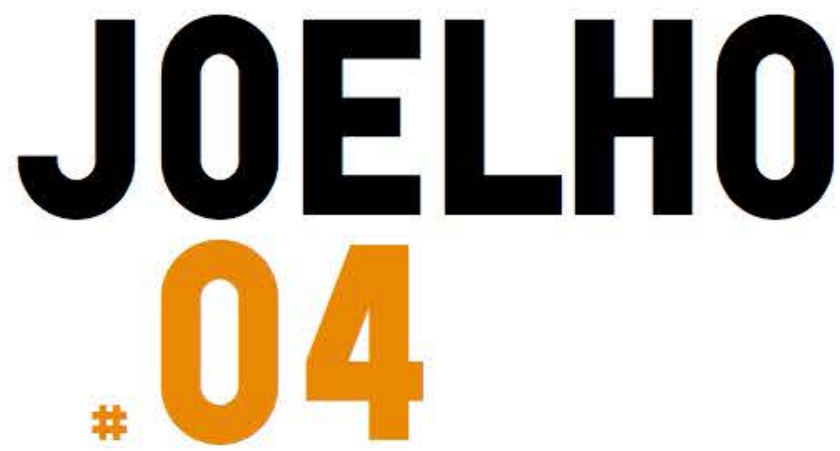

\section{ENSINAR PELO PROJETO \\ TEACHING THROUGH DESIGN}

\section{Coordenaçẫo:}

Paulo Providência

Gonçalo Canto Moniz

Alexandre Alves Costa Juan Domingo Santos Florian Beigel Philip Christou Elizabeth Hatz David Leatherbarrow Andrew Clancy Colm Moore Michael McGarry Willemijn Wilms Floet

Exposição TAPE 20Ir-12 


\section{João Paulo Rapagão, Miguel Malheiro João Paulo Delgado E'difícar pela dissertação. Nexos de coerência entre elaboração do Projecto Final e redacção da dissertação no Mestrado Integrado em Arquitectura}

\section{Objectivo e âmbito}

O objectivo principal desta comunicação é apresentar e discutir uma experiência docente realizada na Faculdade de Arquitectura e Artes da Universidade Lusíada do Porto (FAAULP) em seis anos lectivos consecutivos, de 2006/2007 a 2011/2012. A comunicação dá especial ênfase às metodologias utilizadas para se conseguirem os nexos de coerência mais adequados entre o projecto e a dissertação, e se atingirem os resultados mais satisfatórios em ambos os casos, incluindo trabalhos merecedores de prémios nacionais, como o Prémio Secil ( $f i g .1$ ) e o Prémio da Trienal de Lisboa. ${ }^{1}$

Como se pode perceber por este enunciado, o âmbito da comunicação é essencialmente de ordem operativa e pragmática, como diferenciação de outros, que poderiam ser de cariz doutrinário e programático, e que escapariam tanto à ambição deste trabalho como às actuais competências dos seus redactores.

Durante o período de tempo considerado, os autores da comunicação desempenharam as funções de assistentes da unidade curricular de Projecto III. Nesta condição, participaram também no enquadramento das dissertações realizadas, tanto no que diz respeito aos aspectos formais como às questões temáticas e de conteúdo. A perspectiva aqui adoptada é então a do mediador: aquele que se encarrega de transformar uma directiva (proveniente de uma instância ministerial, profissional ou académica) num resultado simultaneamente válido e valioso.

\section{Contextualização}

O título deste colóquio - Ensinar pelo Projecto - contém a premissa fundamental que o orienta: a de que a actividade projectual propicia, por si e em si, uma acção pedagógica relevante, dentro do elenco curricular de uma faculdade de arquitectura. Esta premissa está de acordo com a tradição das escolas de arquitectura em Portugal, que privilegia a chamada "centralidade do projecto" (Moniz, 2011, pp.545 e segs.), bem como as unidades curriculares com ele relacionadas. No entanto, o Processo de Bolonha veio introduzir algumas alterações que modificaram esta situação, de modo subtil mas muito significativo.

A primeira destas alterações é a própria mutação do nome do grau conferido. $O$ título (que é, sublinhe-se, indispensável para o exercício da profissão) passou de licenciado para mestre. Mais do que uma mera mudança de designação, a alteração contém um peso simbólico e institucional cuja importância não pode ser iludida, mas à qual não tem sido dado o devido relevo. A segunda alteração está directamente ligada com a anterior. Para a obtenção do grau de mestre, torna-se necessária a realização de uma dissertação escrita. Este documento vem acrescentar-se ao trabalho final de projecto, exigido por quase todas as escolas, entre as quais a FAAULP, ao mesmo tempo que substitui a monografia, antes requerida por algumas delas, como por exemplo a FCTUC (Krüger, 2001, p.26).

Para muitos dos cursos de arquitectura anteriores ao Processo de Bolonha, especialmente os que se concluíam em 5 anos, a dissertação pode então considerar-se como o elemento mais evidente 
da diferenciação entre licenciatura e mestrado integrado. A escrita acrescentou-se assim ao desenho, como constituinte fundamental do currículo desses cursos de arquitectura.

\section{Problemática}

As alterações atrás expostas ditaram nos currículos escolares um fenómeno paradoxal: o de uma expansão que se conjuga com uma contracção. A expansão encontra-se no alargamento do conjunto de tarefas e de competências que a redacção da dissertação ditou. A contracção, no tempo exigido para obter o grau, que se fixou em apenas cinco anos. Assim, no derradeiro ano lectivo, os estudantes de mestrado integrado devem dedicar-se ao projecto e à dissertação, enquanto actividades paralelas e simultâneas, embora distintas. Como horizonte ideal, estas actividades devem ser realizadas num ano só, sem interrupções, inícios antecipados ou ultrapassagens do prazo para semestres subsequentes. A dificuldade desta situação reside não só na sua simultaneidade, como também, e acima de tudo, no considerável grau de exigência e de rigor que ambas actividades requerem.

É ainda preciso considerar-se que os instrumentos e as competências indispensáveis para uma actividade são muito diferentes, ou até opostas, às necessárias para a outra. De uma forma esquemática e simplificada, pode dizer-se que a actividade de projecto exige numa delineação gráfica de um pensamento espacial e visual, de tipo criativo e divergente, enquanto a dissertação consiste numa linearização discursiva de um pensamento verbal e lógico, de tipo crítico e convergente (Robertson, 1999, pp.31 e segs).

Por outro lado, uma das principais características de um projecto é a sua especificidade, enquanto uma dissertação deve ambicionar, sempre que possível, a uma certa universalidade (Beaud, 2006, p.27).

Para os docentes, mas também para os estudantes, três questões fundamentais então se colocam. Em primeiro lugar, em que sentido o projecto e a dissertação se podem verdadeiramente integrar, num todo equilibrado e orgânico? Para que essa integração aconteça, quais são as modalidades possíveis de interligação eficaz e operativa? Por fim, como é que esta interligação pode ser mutuamente vantajosa, de tal modo que o desenvolvimento de uma implique necessariamente o benefício directo da outra?

\section{O caso da FAAULP}

Em 2006 ficou concluído o registo da adequação da licenciatura em arquitectura da FAAULP à organização decorrente do Processo de Bolonha. Como na generalidade dos casos semelhantes, a adequação permitiu a obtenção do grau de mestre, em dois ciclos integrados, a decorrer em dez semestres consecutivos, e condicionada à aprovação em 300 ECTS. $^{2}$ De acordo com o respectivo plano de estudos, o último ano do curso ficou constituído por três unidades curriculares: Projecto III (41 ECTS), Ética, Deontologia e Legislação (4 ECTS) e Dissertação (15 ECTS). ${ }^{3}$ A FAAUlp foi assim uma das pioneiras na adopção do modelo de mestrado integrado, tendo sido também percursora na aceitação da dissertação como elemento fundamental do elenco curricular. ${ }^{4}$
Desde então, o 2.0 ano do 2.0 Ciclo dedicou a sua atenção a uma temática de fundo principal: os territórios de fronteira. Esta temática ditou intervenções e projectos nos concelhos de Lisboa, Almada e Barreiro (2006/O7, com participação no concurso para universidades da Trienal de Lisboa), Bragança (2007/08), Porto e Gaia (2008/o9), Caminha (2009/10), Montalegre e Chaves (2010/11) e, por fim, Melgaço (2011/12). Para além disso, tem constituído o referencial fundamental para a elaboração das dissertações.

A concentração temática trouxe algumas vantagens importantes. Para o conjunto dos discentes, proporcionou uma consciência aguda da constituição geográfica e da formação histórica do território, bem como das questões sociológicas, antropológicas, sociais e humanas subjacentes. Consequentemente, gerou uma atitude crítica muito vincada em relação à gestão territorial vigente, ao mesmo tempo que determinou um ponto de vista que privilegia a ligação ao concreto, ao tangível, ao dinâmico e ao incerto, em detrimento de perspectivas mais abstractas, fixas e desligadas da realidade.

Em certa medida, esta abordagem justifica a aproximação verificada em relação a modos alternativos de encarar a arquitectura contemporânea (a geração do Inquérito, o neo-realismo, o neobrutalismo e a Internacional Situacionista, ou a nova escola territorialista italiana, por exemplo), bem como com a existência de um conjunto significativo de investigações em temas correlacionados (as rotas e as derivas, as tipologias construtivas e os assentamentos tradicionais, a tectónica, o ambiente, a materialidade ou a cor).

\section{A emergência de três tipos básicos de dissertação}

Para que esta multiplicidade e variedade tivessem surgido dentro do arco temático adoptado, houve que permitir que, em cada concelho estudado, cada discente dispusesse da máxima liberdade de opção relativamente aos programas a desenvolver e aos assuntos a estudar. Para o projecto final, foram adoptadas três escalas de referência: o desenho de um edifício de equipamento, a organização de um sistema de espaços públicos de um aglomerado médio ou a reabilitação de um aglomerado de pequena dimensão.

Desde o primeiro momento, pareceu evidente que seria benéfica a criação de um elo robusto entre esse projecto final e dissertação.

De entre as muitas vantagens, surgiram estas como as mais evidentes:

- Rentabilização e agilização das fases de levantamento de dados e de recolha e tratamento de informação, necessárias tanto para o projecto como para a dissertação;

- Controlo da quantidade de linhas de investigação a desenvolver durante o ano por cada estudante;

- Utilização do próprio projecto enquanto campo de reflexão e de investigação pessoal, único e irrepetível, com eventual redução do risco de plágio, por um lado, e de redundância ou irrelevância, por outro;

- Cruzamento dos ensinamentos adquiridos e das conclusões extraídas, através de uma pendularidade fecunda e recíproca entre a especificidade do projecto e a universalidade da dissertação. 
O vínculo entre projecto prático e a investigação teórica condicionou, logo a partir dos primeiros trabalhos desenvolvidos, o surgimento de três grupos de dissertações, que podem ser agrupadas de acordo com a seguinte tipologia:

- Tipo 1 ("Fundamentação de Projecto") - A dissertação é a referenciação universalizante e disciplinar do percurso específico empreendido pelo projecto; ${ }^{5}$

- Tipo 2 ("Tema e Caso de Estudo") - A dissertação aprofunda um tema central do universo disciplinar da arquitectura, e o projecto é o caso de estudo que confirma a aplicabilidade concreta dessa investigação;

- Tipo 3 ("Investigação Temática") - Tal como no Tipo 2, a dissertação investiga um tema do universo da arquitectura, o qual, mesmo tendo sido suscitado pelo projecto, pode não ser desenvolvido e ampliado por este.

Apesar de grande parte das dissertações caber de modo nítido num dos três tipos, deve sublinhar-se que existe um número considerável de trabalhos cuja abordagem é mais matizada, constituindo exemplos de transição, nomeadamente entre o Tipo 2 e o Tipo 3. Esta gradação dentro de uma tipologia básica coaduna-se perfeitamente com o que se verifica em países com maior tradição na realização de dissertações. Borden \& Ray (2006) resumem assim a relação entre design studio e dissertation nos países anglo-saxónicos: For some students, the dissertation is seen as an opportunity to take a theme from their designs and to explore this in great depth in the dissertation. For others, the reverse is true, and the dissertation is seen as an opportunity to do something entirely divorced from the design studio which may only later inform design work, or may remain entirely independent of it. For most, it is probably somewhere in between these two extremes (p.6).

A panorâmica citada conclui-se com um conselho pragmático dirigido aos estudantes, e que pode servir de baliza ao leque de opções possíveis: "pick something related to your architectural design interests, but don't make it a slave to studio projects".

Um modo muito directo de perceber a pertença de uma dissertação a cada um ou dois tipos referidos é a análise do índice que resume as matérias tratadas. Assim, para o Tipo 1, o índice regista o topos e o odos do pensamento desenvolvido para a elaboração do projecto, desde a contextualização geográfica e social até à materialização construtiva do objecto arquitectónico proposto. No Tipo 2, a configuração mais comum é a que parte do estado da arte do tema estudado para vir desembocar no caso de estudo proposto. No tipo 3, o índice torna-se mais detalhado nos pontos que se referem à temática, com pouca ou nenhuma referência a uma proposta pessoal. Em todos os tipos se encontram referências e análises de propostas alheias, consideradas respostas exemplares às questões colocadas pela investigação.

De todos os três tipos, aquele que requere maior concentração de esforços para a interligação entre projecto e dissertação é o Tipo 2. O quadro que se apresenta (fig.2) pretende fornecer uma panorâmica dessa concatenação, mostrando a relação entre os aspectos específicos, locais e particularidades do projecto, na coluna da esquerda, e as características universalizantes e gerais da dissertação, ao centro.

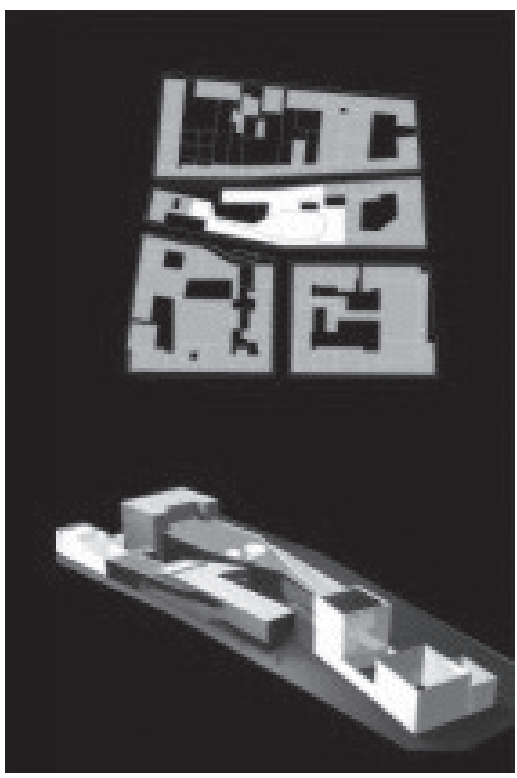

1. Francisco Lencastre. Prémio Secil de Arquitectura Universidades 2007. Desenho do estudante.

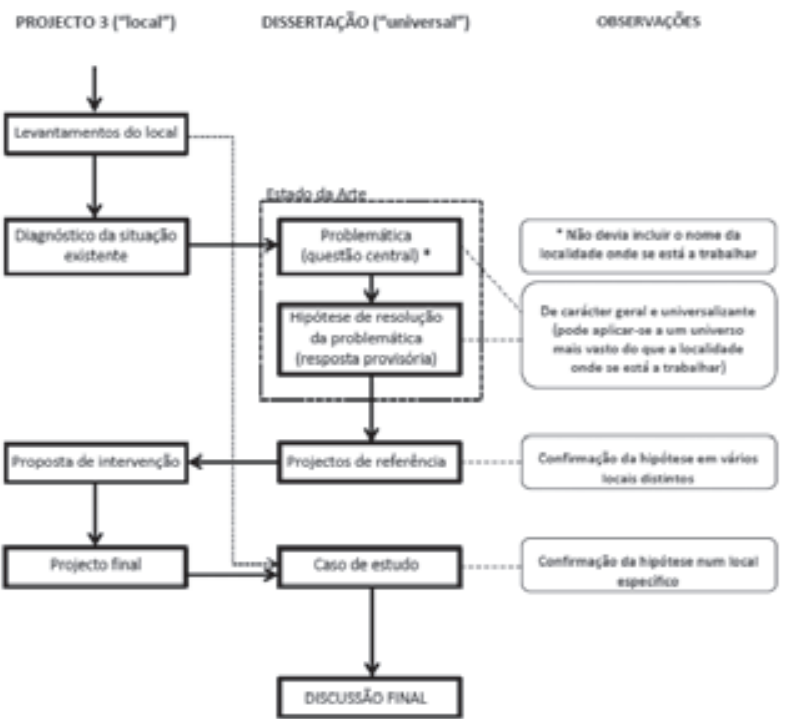

2. Interacção entre Projecto e Dissertação Finais. 
Alguns casos exemplares dos três tipos de dissertação

Como exemplos dos tipos discutidos, bem como de situações de transição, apresentam-se de seguida alguns casos que poderão ilustrar os pontos até agora debatidos. Cada dissertação é apresentada pelo título, pelo autor e pelo índice simplificado. Foram retirados dos índices as referências aos elementos que são comuns a todos (Agradecimentos, Resumo, Abstract, Introdução, Conclusão, Listas, Anexos, Bibliografia). Como modo de comparação, é apresentado um título genérico que designa o trabalho de projecto.

\section{Tipo 1 - Ana Paiva}

Projecto:

Proposta de recuperação, revitalização e salvaguarda do Moinho de Vila Verde da Raia (fig.3)

Dissertação:

"Arquitectura Molinológica: Moinho e açude de Vila Verde da Raia Recuperação, revitalização e salvaguarda"

1. Caracterização física e humana

Contextualização geográfica. Contextualização física. Estrutura geológica e hidrográfica. Contextualização do Moinho de Vila Verde da Raia.

2. Moinhos e sistemas de moagem

Contextualização histórica. Caracterização dos sistemas de moagem.

Caracterização dos moinhos; Levantamento e caracterização do

Moinho de Vila Verde da Raia.

3. Moinhos do concelho de Chaves

Inventariação dos moinhos do Concelho. Tipologias. O futuro dos moinhos.

4. Proposta de recuperação, revitalização e salvaguarda do

Moinho de Vila Verde da Raia

Referências. Programa. Proposta.

\section{Tipo 2 - Susana Oliveira}

Projecto:

Proposta de requalificação do edifício do antigo Casino da Ponte, em Gaia (fig.4)

Dissertação:

"A luz da sombra: Estudo da luz difusa na encosta sombria de Vila Nova de Gaia"

1. Contextualização

As propriedades da sombra e da luz natural. A simbologia da sombra e da luz natural. Os efeitos que a sombra e a luz exercem sobre o ser humano.

2. A essência do lugar

O desenvolvimento de Vila Nova de Gaia. A importância dos vinhos.

A Rua do Casino da Ponte e a Rua Cabo Simão.

3. Diagnóstico do pré-existente

Luz e sombras existentes. Características das aberturas. Os materiais.

4. Projecto de Requalificação

Descrição sintética da intervenção. Método computorizado de análise. A luz difusa. A luz de gruta. A luz de poço. A luz de ascensão. Visão geral do conjunto com os diferentes tipos de luz.
Tipo 3 - José Bastos

Projecto:

Proposta para um museu no concelho de Bragança

Dissertação:

"Construção com desperdícios: Do ambiental ao social" (fig.5)

1. História

Construção com materiais tradicionais. Construção com desperdícios. Síntese.

2. Como resposta a uma crise ambiental

Enquadramento do tema. Casos de estudo - Michael Reynolds e 2012 Architecten - Método. Síntese.

3. Como resposta a uma crise social

Enquadramento do tema. Casos de estudo - I-Beam Design, Shigeru Ban, Sean Godsell, Rural Studio e Santiago Cirugeda - Método. Síntese.

\section{Conclusões}

A experiência aqui debatida permite concluir que, no âmbito dos estudos em arquitectura, é possível integrar uma investigação conducente à redacção de uma dissertação, sem que isto comprometa, mas pelo contrário reforce, o desejado protagonismo do projecto. Para tal, podem ser adoptados pelo menos três tipos básicos de dissertação, verificáveis tanto na forma com que se revestem, como nos conteúdos explorados e desenvolvidos.

A chave reside no justo equilíbrio entre o âmbito e a profundidade da investigação teórica, por um lado, e o labor empírico necessário para a produção de um resultado concreto e tangível, por outro. Os extremos do espectro de soluções possíveis situam-se na elaboração de um estudo monográfico aturado, ainda que irrelevante, e a mera redacção de uma memória descritiva, mais próxima de um relatório profissional do que de um trabalho académico. Qualquer um destes extremos se considera indesejável.

Para a obtenção deste equilíbrio, a coordenação das tarefas lectivas deve concorrer, de modo cada vez mais eficaz, para a realização simultânea de dissertação e projecto, através do estabelecimento de directrizes que esclareçam os graus de dependência mútua entre as duas actividades: destrinça nítida entre efeitos e causas, entre estratégias e tácticas, entre particular e geral. Por fim, porque mais importante, entre o que é local e o que é universal.

As perspectivas que se abrem ao avanço do ensino do projecto são praticamente infinitas, com o consequente incremento da relevância profissional, cultural e social da arquitectura, considerada no seu todo. Este colóquio, ao servir como um balanço das repercussões do Processo de Bolonha em Portugal, proporciona uma oportunidade única para a definição das linhas de investigação mais adequadas à afirmação e consolidação da nossa área do saber junto da comunidade.

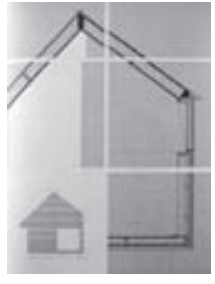

3. Ana Paiva. Desenho da estudante.

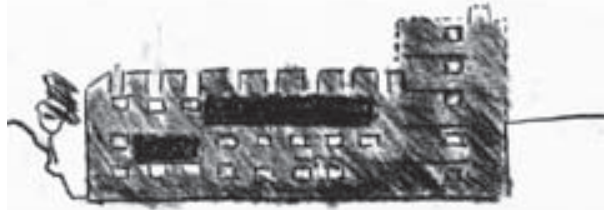

4. Susana Oliveira. Desenho da estudante.

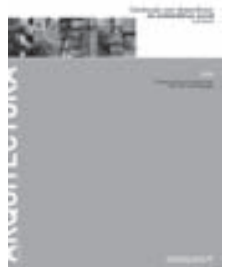

5. José Bastos. Capa da Dissertação do estudante. 
$1 \rightarrow$ Durante este período, os prémios conquistados pelos estudantes da FAAULP foram os que a seguir se indicam. Prémio Secil de Arquitectura Universidades - 2007:

Primeiro Prémio. 2009: Menção Honrosa. 2010: Menção Honrosa. Trienal Internacional de Arquitectura de Lisboa - 2007: Primeiro Prémio e Menção Honrosa. International Velux Award - 2010: Finalista da selecção oficial.

$2 \rightarrow$ Despacho n 13 136/2006 (2a Série), de 07 de Junho de 2006 do Director Geral do Ensino Superior, publicado no Diário da República, 2a Série, n 119, de 22 de Junho de 2006.

$3 \rightarrow$ Consultar http://WWw.por.ulusiada.pt/cursos/1ciclo/1ciclo.php?cp=012

$4 \rightarrow$ As primeiras dissertações foram elaboradas e defendidas logo no ano lectivo de 2006/2007. Até à data de apresentação da comunicação (Setembro de 2012), foram defendidas 480 dissertações, com avaliações entre os 10 e os 19 valores $5 \rightarrow$ A palavra "disciplinar" parece mais apropriada do que o termo "científica", a qual teria que ser utilizada com muita cautela mas com excessiva latitude.

\section{Bibliographical References}

Beaud, M. (2006). L'art de la thèse: Comment préparer et rédiger un mémoire de master, une thèse de doctorat ou tout autre travail universitaire à l'ère du Net. Paris: Editions La Découverte [1985].

Borden, I. Ray, K. R. (2006). The dissertation: An architecture student's handbook. Oxford: Architectural Press [2000].

Krüger, M. J. T. (2001). A Arte de Investigação em Arquitectura, $E C D$ J 5, 22-39. Coimbra: Editorial do Departamento de Arquitectura.
Moniz, G. C. (2011). O Ensino Moderno da Arquitectura: A Reforma de 57 e as Escolas de Belas-Artes em Portugal (1931-69). (Tese de Doutoramento, Coimbra). Acedido em https://estudogeral.sib.uc.pt/bitstream/ 10316/18438/1/GCM-V1-20120301.pdf.

Robertson, S. I. (1999). Types of Thinking. Londres: Routledge. 